\title{
African American Male College Students' Transitioning Experiences at PWCUs and their Coping Strategies: A Qualitative Investigation
}

\author{
Darrick Tovar-Murray, A. J. Metz, and Janice E. Jones
}

Qualitative methodology was used to explore the transitioning experiences of African American males at a large public university in the Midwest. Researchers facilitated a focus group in which seven African American male students described their transitioning experiences and coping strategies attending a predominantly White college and university (PWCU). An interpretative phenomenological approach (IPA) guided by grounded theory was used to analyze the data. Results are discussed with recommendations for researchers and university practitioners.

Understanding the transitioning experiences of African American males attending predominantly White colleges and universities (PWCUs) still remains an important area of research inquiry. For many decades, scholars have identified the personal cognitive variables that affect African American males' academic and social integration at White institutions of higher learning. In fact, there is a plethora of empirical evidence suggesting that low college entrance examination scores and lack of college preparation during high school are reasons that African American males decide to depart from college (Strayhorn, 2008b). However, this body of literature is limited because scholars often use past academic performances to understand college matriculation, failing to consider non-cognitive variables.

Recently, there has been an increased interest among scholars on examining the role that non-cognitive variables played on African American males' college attrition (Tovar-Murray, 2010). Non-cognitive factors such as racial microaggressions have been postulated to hinder African American males academically and socially on PWCU campuses. In other words, scholars have suggested that subtle exchanges of racial indignities can create a negative collegiate racial climate on campus, potentially leading them to leave college (Solórzano, Ceja, \& Yosso, 2000). Given this predicament, researchers and college practitioners have been charged with understanding how African American males cope with racism on PWCU campuses.

Darrick Tovar-Murray (dtovarmu@depaul.edu) is an Assistant Professor in the School of Education at DePaul University.

A. J. Metz (aj.metz@utah.edu) is an Assistant Professor in Counseling Psychology, Professional Counseling, and School Counseling at University of Utah.

Janice E. Jones (j2ejones@stritch.edu) is an Assistant Professor in the Doctoral Leadership Studies Department at Cardinal Stritch University. 
Thus, the general purpose of this study was to explore African American males' transitioning experiences and coping strategies while attending White institutions of higher learning. Important questions such as how do African American males cope with subtle exchanges of racial indignities on college campuses remain unknown. Therefore, an exploration of such a question is our attempt to understand factors that affect their academic and social integration while attending PWCUs.

\section{African American Males and College Departure on PWCUs}

Tinto's (1993) model of college departure has provided scholars and practitioners with a conceptual lens for understanding why African American males depart from college-level education. Tinto posited that college attrition is a function of a student-institution fit, "rather than a psychological phenomenon of the student" (Liu \& Liu, 1999, p. 538). That is, both high quality relationships on campus and student achievement efforts are related to college success. At the heart of the model is the assumption that students depart from institutions of higher learning when there is a lack of confluence. In other words, when institutions provide students with a supportive environment on campus and students are emotionally equipped to manage college life, they are more likely to persist through graduation (Tinto, 1993).

Related to African American males attending PWCUs, Tinto's (1993) model of college departure tends to be supported in the literature. Scholars have found that for African American males, college departure is a function of both the institution's commitment to their needs as well as their own ability to become integrated into college life. For instance, in a recent qualitative study of 13 high achieving African American males, Tovar-Murray (2010) found that supportive efforts from college faculty and same-race peer groups played a major role in their ability to persistent. Results from Strayhorn's (2008b) study have shown that African American males who received support from faculty, staff, and peers tended to report higher levels of satisfaction with college. Still other findings have indicated that social support on college campuses can improve African American males' adjustment to college life (Harper, 2006; Sedlacek, 2004a; Strayhorn \& Terrell, 2007). These results suggest that when African American males experience a supportive racial climate on campuses, they tend to persist. On the other hand, when African American males experience racism on campuses, departure from college life is possible (Solórzano et al., 2000).

\section{Racism and Racial Microaggressions on PWCUs}

Racism is a set of inherent beliefs of White superiority that becomes manifested through individual actions, institutional polices, and cultural practices (Jones, 1997). Racism continues to be an insidious problem for African American males and is enacted on PWCU campuses (Sue, Capodilupo, \& Holder, 2008). For 
example, Solórzano et al. (2000) argued that overt racism on PWCUs can create a negative campus racial climate that limits some African American males from engaging in the campus learning community. Student engagement is defined as "the time and energy that students devote to educationally purposeful activities and the extent to which the institution gets students to participate in activities that lead to student success" (Kezar \& Kinzie, 2006, p. 150). Recently, however, scholars have shifted research efforts from addressing overt acts of racism to implicit expressions of racial microaggressions on student engagement.

Racial microaggressions are defined as subtle exchanges of race threats (i.e., averted gazes, exasperated looks) by Whites directed toward people of color (Delgado \& Stefancic, 2001; Franklin \& Boyd-Franklin, 2000). Recently scholars have used a critical race theory (CRT) framework to explore how racial microaggressions affected African American males' academic and social integration at PWCUs (Solórzano \& Yosso, 2001). The CRT model was developed from the writings of Derrick Bell and Al Freeman who attempted to transform the intersectionality of race, racism, and law during the post-civil rights era (LadsonBillings, 1998). The fundamental basis of CRT is to critique salient issues of racism. At the crux of CRT are the five precepts of centralizing race and racism, commitment to social justice, plurivocality, transdisciplinarity, and challenge orthodoxies (Solórzano \& Yosso, 2001). Proponents of the CRT in education argued that racism is ingrained in the landscape of America and exists on college and university campuses (Solórzano et al., 2000). In other words, to understand why African American males depart from college, an examination of how racism is manifested on campus must be part of the educational discourse.

Racial microaggressions are seldom investigated as possible mechanisms that underlie African American males lack of integration on campus. However, several studies were found that examined how racial microaggressions negatively influence African American males' academic success. For example, Solórzano and associates (2000) conducted a qualitative study using CRT to explore how racial microggressions affected the structure, process, and discourse of a collegiate racial climate among 34 (18 males and 16 females) African American students. In their study, the participants consistently reported that racism made them feel invisible and had a negative impact on the campus's racial climate. Smith, Allen, and Danley, (2007) found that when African American males experience racism on campus they suffer socially. Still, McCabe (2009) found that when compared to other racial groups, African American males tend to report higher rates of experiencing racial stereotypes on campus and frequent interactions with the campus police. In short, these studies conclude that racial micoaggressions are among the reasons that African American males depart from college.

\section{Purpose of this Study}

Although great strides have been made at PWCUs to be more inclusive, more qualitative research is needed to understand how African American males transition on campus. In this study, an interpretative phenomenological analysis 
(IPA) with a "double hermeneutic" approach was used to: "uncovering how African American males make sense of their experiences at PWCUs and interpreting how they understand those experiences" (Smith, 2004, p. 40).

Therefore, this study was guided by the following questions:

- What challenges do African American males face while transitioning on PWCUs?

- What are African American males' perceptions of the racial campus climate at PWCUs?

- How do African American males cope with racial microaggressions at PWCUs?

\section{Method}

\section{Participants}

Seven African American males attending a large public university in the Midwest participated in this study. Participants ranged in age from 22 to 26. Five were undergraduate students, one was a graduate student, and one was an alumnus who graduated with a master's degree the previous year. Students were initially identified via chain referral sampling, a type of purposive sampling used when a limited number of participants are available. A benefit to this sampling method is that data may be "rich" as participants are asked to recommend other participants that seem appropriate. The drawback to using this method of sampling is the increased risk of bias to the study (Patton, 2002). To control for this, researchers asked participants to not only recommend their friends, but other African American males who they had contact with through classes, work, or student organizations. Furthermore, the researchers documented and discussed potential biases throughout the course of this study.

Credibility with African American male students was important to establish. To increase trust of potential research participants, the African American male researcher, a well-connected and respected professor, helped one of the European American female researchers network with African American male students. After establishing connections, researchers began to recruit participants and asked them to recommend others. Those who agreed to participate in the study were given a letter outlining the general purpose of the study, confidentiality expectations, and information regarding the day, time, and location of the focus group.

\section{Data Collection}

A semi-structured interview protocol was created to explore participants' transitioning experiences and coping strategies attending PWCUs. As recommended by Smith (2004) for a well-designed focus group using IPA, there were at least seven participants. The focus group was scheduled at noon on a weekday and lunch was provided. Researchers introduced themselves to participants, described 
the purpose of the study, provided an overview of the structure of the focus group, collected demographic information, and responded to participants' questions and concerns. Participants responded to a series of open-ended questions that focused on the challenges they faced on PWCU campuses, how they cope with those challenges, and how the university can help them to integrate on campus. Sample questions were:

- What are some of the challenges you face on campus?

- What are some of your transitioning concerns?

- How do you deal with these challenges?

- What would help you to deal with these challenges?

To protect confidentiality, participants were asked to provide pseudonyms that were written on place cards and used for the duration of the focus group and data analysis. Informed consent was obtained from all participants before beginning the discussion. The focus group was audio-taped and following completion of the focus group, the audio-tapes were transcribed verbatim by the researchers. During the focus group, the participants engaged in a dialogue about their academic and social experiences on campus. Participants' observations regarding how they responded to questions and their willingness to engage in the focus group were recorded. Researchers noted themes and issues that occurred during the focus group interview.

\section{Qualitative Data Analysis}

The rigorous principles of IPA outlined by Smith (2004) were used to analyze data. In the first stage, the primary research team read the focus group transcripts. Each member noted what the participants said and how they responded to the questions. After focusing on what each respondent said, the second stage involved the team re-reading the transcripts. At this time themes were developed and abstracted from the text. The final stage consisted of clustering the themes and looking for conceptual similarities. This stage involved the research team taking the conceptual similarities and developing a table of super-ordinate themes with master and sub-themes (Smith \& Osborn, 2004).

To ensure the authenticity of findings, the researchers provided the participants detailed accounts of their narratives for their concordance. To increase the credibility of findings, the researchers triangulated the data with multiple data sources such as member check, literature reviews, and field notes (Denzin \& Lincoln, 2003). Furthermore, in order to reduce researchers' biases (Lincoln \& Guba, 1985), a third researcher, who was not part of the data collection, was recruited (Denzin \& Lincoln, 2003) and given copies of the transcripts' coded categories to review and provided feedback. 


\section{Results}

Several super-ordinate themes clustered around the participants' accounts emerged from the data. These super-ordinate themes consisted of: Psychosocial Stressors, Racial Microagressions, and Coping and Transitioning Capacity. The numerical coding of the super-ordinate themes with their corresponding master themes and subthemes are presented in Table 1. Each theme is provided with specific examples from the participants' narrative accounts.

\section{Psychosocial Stressors (Code 1)}

General Life Stressors (1.1). The first master theme identified by the participants in this study was general life stressors which captured participants' everyday challenges to daily living as they transitioned on campus. The most frequently reported general life stressor was lack of money (1.1.1). All seven participants described that they experienced financial difficulties and had to negotiate work and school while attending college. One participant, Captain, discussed how working affected his ability to maintain "good" grades.

I had to help pay bills. I had two jobs...plus played football. I mean, how much of my time do I really have? I'm not saying I had to have both of those jobs, but I need to help out my family. Now, most of the plight of the Black man in college is trying to figure out how to get this done. I spend so much time worrying about how I'm going to pay for this school that I don't have enough time to concentrate on the school.

In response, the other six men nodded their heads in agreement. They all agreed that if they didn't work, they wouldn't be able to pay for school and help family members pay bills. Two participants also reported dropping out of college for a semester or more to pay bills.

More than half of the participants identified managing multiple roles (1.1.2) as another general life stressor. For example, they listed student government, student organizations, and fraternities as campus activities they felt committed to on top of work and school. Participants also complained that they had "full" course loads and felt there just weren't enough hours in the day to accomplish everything. One participant, Rick summarized what he thought everyone in the room was feeling and said,

All of us in here are involved in some form or fashion... and all of us sitting here are burned out...you do break down, and you get busted, and you start to get frustrated.

At this moment, the participants' emotions ran high as Captain echoed Rick's sentiment and replied,

It feels like anytime I sit down, even if it's to eat, I should be doing something. Anytime, if you stop, if you breathe...oh man, I got this homework, two 
quizzes, etc. You feel like you're stuck.

Participants ended the discussion of general life stressors with describing their relationships with prominent others as "stressful" and acknowledged spending "a lot" of time trying to stay connected with their family and home community (1.1.3). For example, Clark stated,

I've got five brothers and three sisters, and it makes me sick. I've missed out on them growing up. So I've had to switch my whole purpose to as far as being a students and a brother. I realized I was spending so much time getting involved with community organizations, trying to help as much as possible. I just got burnt out. My grades suffered.

\section{Racial Microaggressions (Code 2)}

Race-related stressors (2.1). The master theme of race-related stressors designated specific acts of racial microaggressions in which the participants felt they were assessed based on negative stereotypes about their Blackness. There was agreement among the participants that race-related stressors appeared to be constantly present in their lives. An example of racial microaggressions on campus is evident in John's statement, as he heard Whites make comments such as, "a Black man is supposed to get shot or be in jail by the age of $18 . "$

Each participant reported experiencing race-related stressors on campus within a week or month prior to the study. They reported experiencing the stressors of racism in public spaces, in classroom settings, and on the job. One of the most cited race-related stressor was in public spaces (2.1.1) on campus. For example, Simi shared a story of walking on campus and feeling racially slighted by those of the majority group. He said,

Some white people cross the other side of the street to avoid walking passing me on campus. Some Whites are actually fearful of the Black man, [and] more fearful of an intelligent Black man.

Another common theme repeated in all interviews was that race-related stress exists in the classroom setting (2.1.2). Randy added to this notion, sharing his disappointment in being the only person of color in many of his courses and being asked to speak "for every Black person in history." Describing his experience, Rick said "the classrooms are not geared towards anybody who is the other," meaning Black. He furthered explained, "We have to work twice as hard as anybody to be seen as an equal."

More than half of the participants reported that they experienced race-related stress on the job (2.1.3) at the university they attended. This notion was bested illustrated by Clark, who said that as a supervisor there have been times he felt his White employees were being disrespectful and condescending based on his skin color. He explained,

I see someone at least at work...I confront it...I don't like people talking down to me and then acting like they don't know what they're talking about... I say, 
no, you are doing that... You're being condescending. You're talking down to me, and I don't like that. At that point, a lot of people were making the extra concerted effort to make sure they weren't doing that. Some people may or may not realize they are doing that.

All of the participants agreed with Clark and laughed. They also acknowledged that whether one is experiencing racism on or off campus, it is important for them to confront it and provide teachable moments. They ended this segment of the interview describing that no matter how they handle racism on campus, it is important for them to maintain a sense of dignity and respect.

\section{Coping and Transitioning Capacity (Code 3)}

Coping Strategies (3.1). The master theme of coping strategies focused on how the participants dealt with general life and racism-related stressors. These coping strategies identified ways in which African American males in this study managed stressful events, regulated their emotions, or solved problems. Many of the participants endorsed social comparison (3.1.1) as a coping strategy for dealing with their concerns. When faced with stress, the participants stated that they use a "downward comparison approach" by mentally shifting their focus from evaluating themselves to examining the achievement and abilities of others who were "worse off" than them. The basic idea here is that the participants tend to defend themselves by comparing themselves to others who are less fortunate to cope with stress.

Some of the participants employed cognitive coping strategies (3.1.2) to deal with general life and race-related stressors. Cognitive coping strategies were described by the participants as modifications in thought and "thinking outside of the box." Rick suggested that "Minorities learn to think outside the box because they've been outside the box for so long." Others said they try to cognitively ignore, deny, or dismiss issues. In addressing racism, two participants said they "just expect it," by not saying or doing anything about it.

Behavioral coping strategies (3.1.3) were also described by the participants as ways to cope with stressors on PWCUs. Behavioral coping strategies referred to specific physical actions to manage stress. They identified the following behavioral coping strategies: playing basketball and pool, hanging out with friends, being around family, listening to and making music, playing video games, and writing. Participants also identified other strategies (3.1.4) for dealing with stressors on campus. Three participants shared that using humor helps them to cope. Simi deals with racism on campus in the following way:

It becomes second nature. I laugh at it...some people are actually fearful of the [Black] man, more fearful of an intelligent [Black] man. When you get those two things combined, it is like, you might be able to rob me and get away with it. You just got to laugh at it.

Again this notion of Whites being fearful of an intelligent Black man became 
a reoccurring theme. Others said they learned how to talk themselves into moving forward, and this was expressed by Clark as "stick-to-it-ness" (3.1.5). Anthony said that he talks to his grandmother on a regular basis who tells him to "meditate, meditate." Others shared that they address racism on campus by confronting race-related incidences, while some described creating "teachable moments" after a racist encounter. Randy explained, "Sometimes you have to be the mouthpiece, advocate, everything...sometimes they (Whites) just need education. Sometimes you need to break down the walls...barriers."

Finally, the participants said that they use spiritual and religious coping (3.1.6) to deal with stress, and their faith in God "kept them going." When discussing using faith as a coping strategy, Anthony replied, "I put things in God's hands. For me to sit and worry about stuff I can't control is stupid, and it just adds more stress."

\section{Discussion}

Research examining African American males' experiences attending PWCUs has documented their significant transitioning concerns. This body of work has led to a call to the profession to understand how they cope with racial microaggressions on campus (Solórzano et al., 2000; Solórzano \& Yosso, 2001). But many questions remain, including how racism and general life stressors may influence African American males to depart from college. This study added to the extant literature by providing an in-depth look at the transitioning experiences of African American males who attend a PWCU and by gaining a better understanding of their coping strategies. Therefore, what follows is a discussion of the results, followed by implications for university practitioners.

In general, study findings were congruent with previous research. First, the participants in this study reported that racism was a unique source of stress that they experienced on PWCU campuses. This finding seems to support other researchers who asserted that racism is a part of everyday life for African American males that shapes their experiences in both academic and social spaces on campus (Solórzano et al., 2000). On a similar note, results indicated that a lack of money and an inability to manage multiple roles was related to these African American males' persistence in college. Therefore, understanding how both general life and race-related stressors might detract African American males from college life does have theoretical significance. However, this study did not quantify the relationship among general life and race-related stressors and academic departure. Further comparisons between this study, previous, and future work is warranted.

Second, many of the African American males in this study recounted stories of having to deal with general life and race-related stressors on campus, and it was speculated that this could have played a key role in their ability to feel connected on campus. The result here is grounded in Tinto's (1993) notion of social integration. In other words, the extent to which African American males feel supported by others on campus might help them to become academically and socially tied to campus life. This need for social support was evident in the 
participants' narratives as they made numerous attempts to stay connected with their host communities. Moreover, when faced with racial microaggressions on campus, these African American males also preferred to connect with family and friends for help.

Finally, many of the participants in this study reported that they used a variety of cognitive and behavioral strategies to deal with transitioning concerns on campus. For example, thinking outside of the box, ignoring racial stereotypes, playing sports, listening to music, and laughing at stereotypical threats were identified as coping strategies. At the same time, the participants said that they tend to seek out support from spiritual and religious institutions to cope with stressors on campus. The results of this study are consistent with other studies (DilworthAnderson, Williams, \& Gibson, 2002; Tovar-Murray, 2010), and found that African American males were most likely to seek out religious resources to manage transitioning concerns.

\section{Implications for Student Affairs Professionals}

As African American men experience significant life stressors that may impact their academic and social status on PWCUs, it is imperative that university administrators, staff, and faculty make a commitment to better serve them. This commitment needs to be addressed not only in attitudes and beliefs, but in action. A number of recommendations seem warranted based on the findings of this study. First, PWCUs should formalize a mission to increase and better serve African American males. A dedicated and active committee should be formed that establishes specific, measureable, attainable, realistic, and timely goals to ensure this mission is realized. Administrators, staff, and faculty at PWCUs need to be open to listening to the perspectives and needs of this population. They should also be willing to discuss racism, discrimination, and other institutional barriers faced by these students. Moreover, PWCUs need to address financial issues that seem to impact African American male students' academic success.

Second, recruitment efforts (i.e., pre-college and summer bridge programs) could be geared towards actively integrating African American males in the campus community. PWCUs may want to establish partnerships with local high schools and community organizations to gain trust and build goodwill. Getting in touch with diverse local high school students may help universities assess transition challenges and supports. Furthermore, traditional marketing techniques may need to be supplemented to reach African American males. One suggestion is for practitioners to promote events at particular locations (e.g., recreation center, basketball games, fraternity house) that African American males frequent. Participants in this study suggested that university personnel could hand out "cool" logo-items (pens, stress balls) so they would have the contact information easily available and identifiable when needed. In addition to passive programming, it seems important to engage African American males in conversations and develop a personal relationship with them.

Third, university personnel may need to take proactive efforts in connecting 
African American men with faculty, staff, and peers to form the social capital needed to persist through graduation (Strayhorn, 2008b). Specifically, one-on-one mentoring and tutoring programs are important for academic success. University outreach activities should continue to challenge stereotype threats associated with African American males and find ways to integrate them on campus (e.g., Real Men Program, Providing Access Through Holistic Support). Interestingly, the student affairs division that supported this study had an extensive outreach program, yet five of the seven participants did not know that services were available for them to meet their needs. This finding speaks to the importance of visibility and dissemination of information. It may be important for university personnel to explore different message delivery strategies to get African American males' attention and provide them with information. Some possible examples include experimenting with posters in the locker room, a weekly column in the student newspaper, text messages, iPod downloads, or e-mailing short video-clips. A focus group of African American males may be able to brainstorm additional strategies for reaching out.

Finally, university personnel should continue to make college a welcoming and supportive environment for African American males. This might be accomplished by ensuring African American males see posters of role models or pictures of the diverse campus climate. PWCUs could then create a "best-practice for welcoming African American males" handout or website. Moreover, it would be important for PWCUs to develop and advertise programs that speak directly to issues affecting African American males and target these programs as building on their academic strengths and social development. To this end, universities should take a more aggressive recruitment stance on attracting and retaining more African American faculty and staff members.

\section{Limitations}

There are a number of limitations to this research study. For example, the chain referral sampling method may have affected participants' responses, as many knew each other. This research was conducted at one university located in the Midwestern region of the United States, adding to the difficulty in generalizing the results to other populations. However, these limitations should not distract the reader from the importance of the findings as they pertain to African American males' transitioning experiences and coping strategies attending PWCUs. Furthermore, although the males in this study identified numerous transitioning concerns that impacted them on campus, they also described several race-related stressors. It would be interesting to quantitatively study the relative importance of each type of stressors (i.e., in public spaces, in classroom settings, and on the job) on their academic success. Finally, future research should empirically examine the relative effectiveness of specific coping strategies on African American males' academic and social integration. 
Delgado, R., \& Stefancic, J. (2001). Critical race theory: An introduction. New York: New York University Press.

Denzin, N. K., \& Lincoln, Y. S. (Eds.). (2003). Collecting and interpreting qualitative materials (2nd ed.). Thousand Oaks, CA: Sage.

Dilworth-Anderson, P., Williams, I. C., \& Gibson, B. E. (2002). Issues of race, ethnicity, and culture in caregiving research: A 20-year review (1980-2000). The Gerontologist, 42(2), 237-272.

Franklin, A. J., \& Boyd-Franklin, N. (2000). Invisibility syndrome: A clinical model of the effects of racism on African-American males. American Journal of Orthopsychiatry, 70(1), 33-41.

Harper, S. R. (2006). Peer support for African American male college achievement: Beyond internalized racism and the burden of "acting White." The Journal of Men's Studies, 14(3), 337-358.

Jones, J. M. (1997). Prejudice and racism (2nd ed.). New York: McGraw-Hill.

Kezar, A. J., \& Kinzie, J. L. (2006). Examining the ways institutions create student engagement: The role of mission. Journal of College Student Development, 47(2), 149-172.

Ladson-Billings, G. (1998). Just what is critical race theory and what's it doing in a nice field like education? International Journal of Qualitative Studies in Education, 11(1), 7-24.

Lincoln, Y. S., \& Guba, E. G. (1985). Naturalistic inquiry. Beverly Hills, CA: Sage. Liu, E., \& Liu, R. (1999). An application of Tinto's model at a commuter campus. Education, 119(3), 537-542.

McCabe, J. (2009). Racial and gender, microaggressions on a predominately-White campus: Experiences of Black, Latina/o and White undergraduates. Race, Gender \& Class, 16, (1), 133-151.

Patton, M. Q. (2002). Qualitative research \& evaluation methods (3rd ed.). Thousand Oaks, CA: Sage Publications.

Sedlacek, W. E. (2004a). Beyond the big test: Noncognitive assessment in higher education. San Francisco: Jossey-Bass.

Smith, J. A. (2004). Reflecting on the development of interpretative phenomenological analysis and its contribution to qualitative research in psychology. Qualitative Research in Psychology, 1, 39-54.

Smith, J. A., \& Osborn, M. (2004). Interpretative phenomenological analysis. In G. Breakwell (Ed.), Doing Social Psychology (pp. 229-254).Oxford, England: Blackwell.

Smith, W. A., Allen, W. R., \& Danley, L. L. (2007). Assume the position...you fit the description: Psychosocial experiences and racial battle fatigue among African American male college students. American Behavioral Scientist, 51 (4), 551-578.

Solórzano, D. G., Ceja, M., \& Yosso, T. J. (2000). Critical race theory, racial microaggressions, and campus racial climate: The experiences of African American college students. The Journal of Negro Education, 69(1-2), 60-73. 
Solórzano, D. G., \& Yosso, T. J. (2001). Critical race and latcrit theory and method: Counter- storytelling. International Journal of Qualitative Studies in Education, $14(4), 471-495$.

Strayhorn, T. L. (2008b). The role of supportive relationships in facilitating African American males' success in college. NASPA Journal, 45(1), 26-48.

Strayhorn, T. L., \& Terrell, M. C. (2007). Mentoring and satisfaction with college for Black students. The Negro Educational Review, 58(1-2), 69-83.

Sue, D. W., Capodilupo, C. M., \& Holder, A. M. B. (2008). Racial microaggressions in the life experience of Black Americans. Professional Psychology: Research \& Practice, 39(3), 329-336.

Tinto, V. (1993). Leaving college: Rethinking the causes and cures of student attrition (2nd ed.). Chicago: University of Chicago Press.

Tovar-Murray, D. (2010). The narrative experiences of undergraduate African American male students, 24 years and younger, who successfully transitioned to and persisted in college life. The Journal of College Orientation and Transition, $17(2), 5-17$.

\section{TABTE 1}

\section{Compositional Structure of IPA Themes.}

\section{Code Super-ordinate themes Code Master themes Code Subthemes}

1. Psychosocial Stressors $\quad 1.1 \quad$ General Life Stress $\quad$ 1.1.1 Lack of Money

1.1.2 Managing Multiple Roles

1.1.3 Staying Connected

2. Racial Microaggressions $2.1 \quad$ Race-related Stress

2.1.1 In public spaces

2.1.2 In classroom setting

2.1.3 On the job

3. Coping and Transitioning $3.1 \quad$ Coping Strategies

3.1.1 Social comparison

3.1.2 Cognitive strategies

3.1.3 Behavioral strategies

3.1.4 Other strategies

3.1.5 Stick-to-it-ness

3.1.6 Religious coping

Note. Code indicates thematic hierarchy. 